\title{
Polymorphisms of Q-band Heterochromatin: Qualitative and Quantitative Analyses of Features in 3 Ethnic Groups (Europeans, Indians, and Turks)
}

\author{
L. Kalz, B. Kalz-Füller, S. Hegde* and G. Schwanitz \\ Institute for Human Genetics, Bonn, Germany \\ *Manipal Hospital, Bangalore, India
}

\begin{abstract}
KEYWORDS Human constitutive heterochromatin; fluorescence polymorphisms i(5); population genetics; European, Indian, and Turkish genetic relations; chromosome-specific polymorphisms; heterochromatin in acrocentric chromosomes.
\end{abstract}

\begin{abstract}
Focusing predominantly on fluorescence polymorphisms i(5) after QFQ-banding and some CBG banding in lymphocyte cultures, the comparison of polymorphisms of constitutive heterochromatin in the chromosomes 1, 3, 4, 9, 13, 14, 15, 16, 21, 22, and Y of Central Europeans with those of Indians and Turks showed insignificant differences in the sizes vs and $\mathrm{m}$ but significant differences in the size $\mathrm{s}$ with the highest number in the Indian group. Differences in fluorescence $\mathrm{i}(5)$ proved to be statistically highly significant among the 3 groups as well as differences in the duplication of the satellite stalk (p12) of the acrocentric chromosomes. The number of fluorescence i(5) per case was highest in the Indian and lowest in the Turkish group. The comparison of polymorphisms revealed the least number of differences to exist between Europeans and Indians, followed by Europeans and Turks, with Turks and Indians having the highest number of significant differences.
\end{abstract}

\section{INTRODUCTION}

Studies in population genetics can analyse differences in various ethnic groups, usually documenting traits that follow monogenetic inheritance and thus characterizing one population in comparison to others. Monogenetic polymorphisms show up in at least 2 alleles and are of no negative consequence to the carrier. Polymorphisms of the highly repetitive DNA of the chromosomes are increasingly being used for population studies. These polymorphisms of the human chromosomes are regions of constitutive heterochromatin, preferentially in intrachromosomal positions defining segments that do not decondense in the telophase of mitosis, but stay condensed during the interphase and remain transcriptionally inactive on a permanent basis.

Various investigations have been performed on the human constitutive heterochromatin with divergent methods applied in these individual studies. The regions were preferably analysed following CBG- or QFQ-staining.

The goal of our investigations was the comparison of polymorphisms in a Central European population with 2 populations of different ethnic origin.

\section{MATERIAL AND METHODS OF INVESTIGATION}

Chromosomes of 100 non-related Central Europeans were analysed and compared with 67 persons from Southern India and 100 from Turkey using lymphocyte cultures and a comparable distribution of male and female cases. Altogether, 10,680 regions on 534 autosomes and, additionally, Yq12 in 121 males, were investigated focusing on polymorphisms after QFQ-staining. 3 types of regions were analysed: the autosomes in the pericentromeric positions: 1q12, 3q11.2, $4 \mathrm{q} 11.2,9 \mathrm{q} 12,16 \mathrm{q} 11.2$, then the entire short arms of the acrocentric chromosomes 13, 14, 15, 21, and 22, divided in p11.2, p12, and p13, plus the distal band Yq12. All polymorphisms on the autosomes were analysed twice. The individual polymorphic region was documented according to size, fluorescence intensitiy (i5), and localization.

The standard of deviation of polymorphism frequency depended upon the individual population.

Photos were taken of the c-metaphases, and the analyses were performed on negatives, using a special apparatus enlarging the negative 10- 
fold. At least 6 mitoses per case were evaluated. In case of problems, the number of mitoses was increased to 20 . The definition of the polymorphisms was in accordance with the international nomenclature ISCN (1995), (size: very small to large), taking into consideration only a brilliant fluorescence i(5).

Statistically, the significance of differences observed was checked favouring the Chi-square distribution in non-parametric tests.

\section{RESULTS}

In the present investigation, the peculiarities of the chromosome regions were obtained first [size: vs, s, m, and brilliant fluorescence of the intensity $\mathrm{i}(5)$ ] followed by analyses of the frequencies of mutations (dup, del, inv). The results were then compared for the 3 ethnic groups to determine their similarities and differences.

Polymorphisms of the chromosomes $1,3,4$, $9,13,14,15,16,21,22$, and $\mathrm{Y}$ were characterized in the 3 investigation groups consisting of 100 Europeans (E), 67 Indians (I), and 100 Turks (T), with emphasis on fluorescence intensity $\mathrm{i}(5)$ following QFQ-staining. 10,680 chromosome regions in 267 persons were analysed using lymphocyte cultures.

Polymorphisms of Size: After QFQ-staining (fluorescence-polymorphisms) they were analysed in the chromosomes $3,4,13,14,15,21$, and 22. They could be observed in $87.0 \%$ of the investigation group E, $87.8 \%$ of the group I, and $86.8 \%$ of the group $\mathrm{T}$, the difference being insignificant (Kalz 2003). In contrast, the comparison of polymorphism frequency in either one of the size classes vs, $\mathrm{s}$, and $\mathrm{m}$ revealed a significant difference for some of the parameters in all 3 ethnic groups (Table 2). While the sizes vs and $\mathrm{m}$ did not show any significant differences $(96.3 \%, 95.2 \%$, and $96.9 \%$ for vs and $0.2 \%, 0 \%$, and $0,2 \%$ for $\mathrm{m}$ ), size s was significantly different in frequency with $3.5 \%$ for E, $4.8 \%$ for I, and 2.9 $\%$ for T (Fig. 1).

Fluorescence Polymorphisms i(5): In the above-mentioned 7 chromosomes after QFQstaining, the polymorphic regions were determined in 18,5\% (E), $22.8 \%(\mathrm{I})$, and $14,9 \%$ (T) of the total amount of the relevant chromosomes analysed. The differences in fluorescence $\mathrm{i}(5)$ between the 3 groups proved to be statistically highly significant, as well as the difference in frequency in chromosome regions with fluorescence and structural polymorphisms combined $(21.2 \%, 26.0 \%, 17.2$ \%) (Fig. 2).

Number of Fluorescence Polymorphisms per Case: Fluorescence polymorphisms in the individual probants ranged from 0 to 15 , showing a maximum of 4 in group E, 5 in group I, and 3 in group T (Fig. 3). The mean distribution is highly significantly different in all 3 groups.

Length of Yq12: The average size of the Ychromosome polymorphism showed a maximum at $30 \%$ in all 3 groups with no significant differences in the mean distribution.

Polymorphisms of Size After QFQ- and CBG-Staining Analysed in the Chromosomes 1, 9, And 16: For all 3 chromosomes, duplications of size of the constitutive heterochromatin were detected in $19,5 \%$ for E, $25,4 \%$ for I, and $28,5 \%$

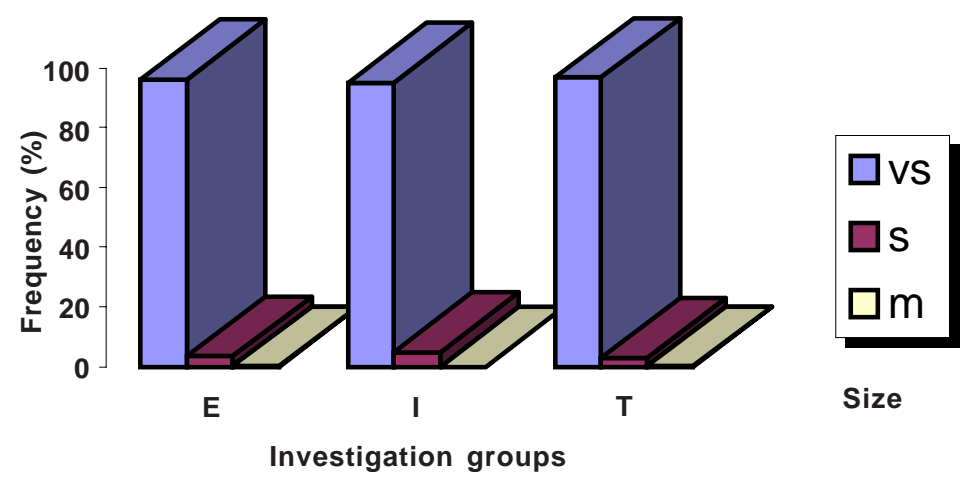

Fig. 1. Polymorphisms of size vs, $s$, and $m$ in the 3 analysed investigation groups $E$, $I$, and T $(\mathbf{E}=$ Europeans; $\mathbf{I}=$ Indians; $\mathbf{T}=$ Turks; vs = very small; $\mathbf{s}=$ small; $\mathbf{m}=$ medium $)$ 


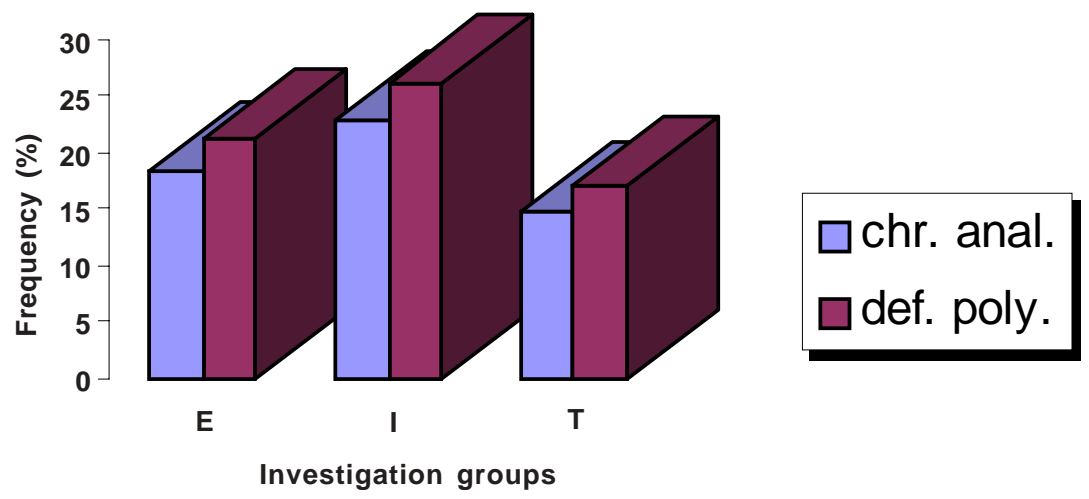

Fig. 2. Frequency of fluorescence polymorphisms i(5) in the 3 analysed investigation groups E, I, and $\mathrm{T}$, refering to the total number of chromosomes analysed (blue) and to defined chromosomes with fluorescence and structural polymorphisms combined (red) (abbreviations see Fig. 1; chr. anal. = chromosomes analysed; def. poly. = defined polymorphisms).

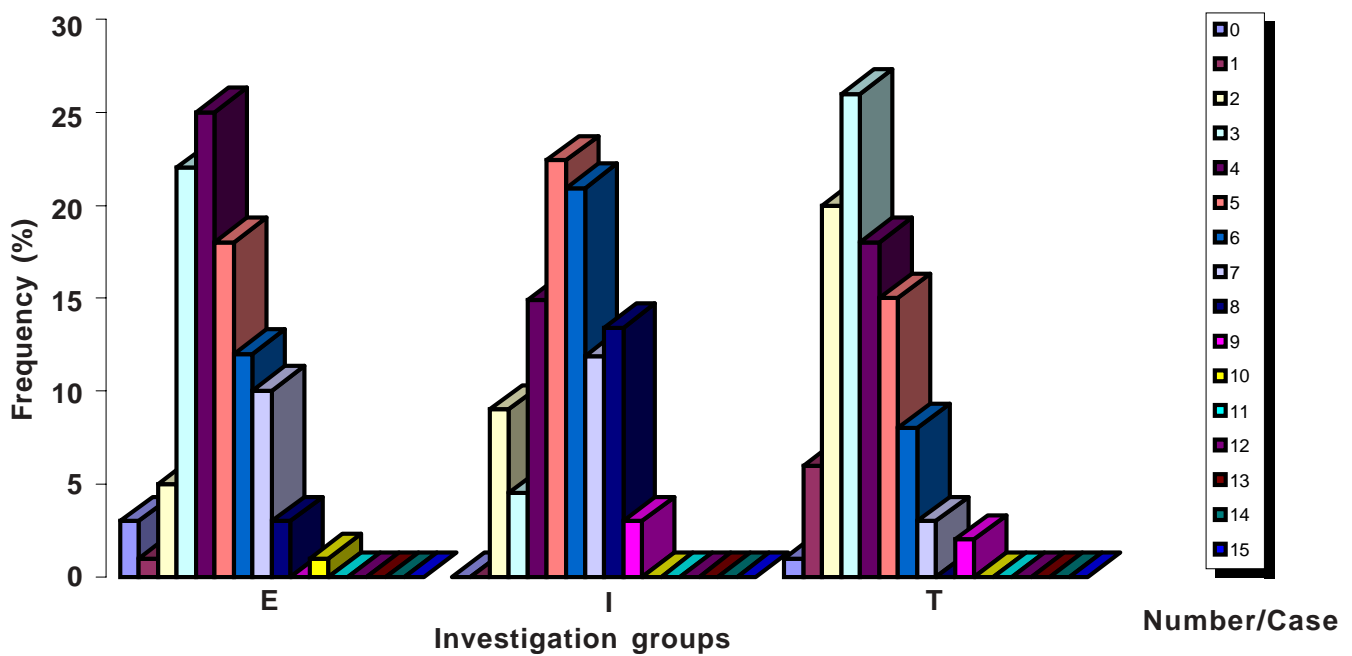

Fig. 3. Distribution of fluorescence polymorphisms i(5) per case in the 3 investigation groups E, I, and $\mathrm{T}$, the number ranging from 0 to 15 (analysis of 24 chromosome regions on 7 pairs of chromosomes, abbreviations see Fig. 1).

for T. Differentiated according to the single chromosome, the frequencies were found in 4.5 $\%, 3.7 \%$, and $10.5 \%$ in chromosome $1,14.0 \%$, $20.2 \%$, and $15.0 \%$ in chromosome 9 , and $1.0 \%$, $1,5 \%$, and $3,0 \%$ in chromosome 16 . Only the differences between $\mathrm{E}$ and $\mathrm{T}$ on the one hand and $\mathrm{T}$ and $\mathrm{I}$ on the other in chromosome 1 were statistically significant.

Duplication of the Satellite Stalk (p12) of the Acrocentric Chromosomes: This parameter showed an average frequency of $1.0 \%$ for E, 8.4 $\%$ for $\mathrm{I}$, and $0.1 \%$ for $\mathrm{T}$, thus revealing a statistically significant difference between $\mathrm{E}$ and $\mathrm{T}$ and a highly significant difference between $\mathrm{E}$ and I as well as T and I (Fig. 4).

Doubled Satellites (ss) in p13 of the Acrocentric Chromosomes: Frequencies of $0.3 \%$ in group E, $0.2 \%$ in $\mathrm{I}$, and $0.8 \%$ in $\mathrm{T}$ were diagnosed, with no significant differences between the 3 ethnic groups.

Complete Pericentric Inversions of the Constitutive Heterochromatin: This specific type of intrachromosomal rearrangement occurred in the chromosomes $1,3,4,9$, and 16 . The fre- 


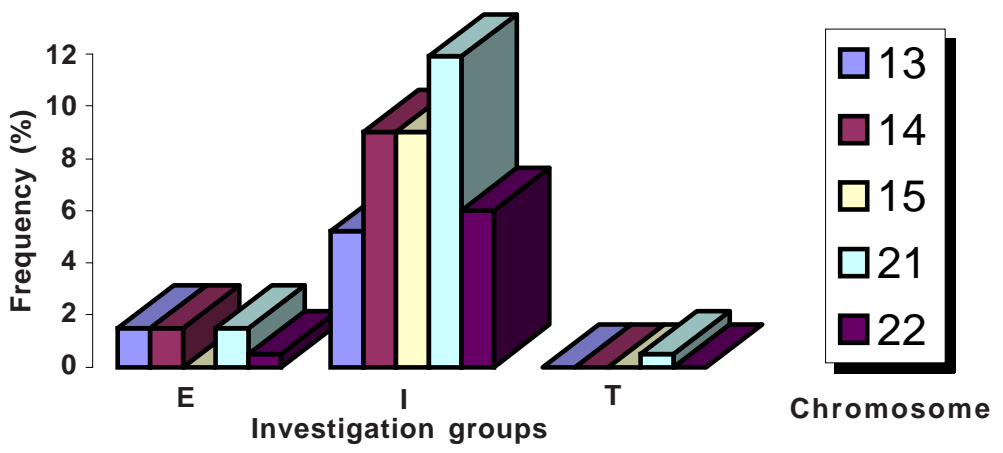

Fig. 4. Frequency of duplication of the satellite stalk (p12) in the acrocentric chromosomes of the 3 investigation groups $\mathrm{E}$, $\mathrm{I}$, and $\mathrm{T}$ (abbreviations see figure 1).

quencies showed significant interchromosomal differences and amounted to $0 \%$ for chromosome 1 and 16 in all the 3 groups, for chromosome 3 to $0 \%(\mathrm{E}), 0.8 \%(\mathrm{I}), 0.5 \%(\mathrm{~T})$, for chromosome 4 to $2.5 \%(\mathrm{E}), 6.7 \%(\mathrm{I}), 2.0 \%(\mathrm{~T})$, for chromosome 9 to $0.5 \%(\mathrm{E}), 1.5 \%(\mathrm{I}) 0.5 \%(\mathrm{~T})$ (Table 1$)$, determined in relation to the number of chromosomes analysed. The frequency of inversions became more striking when related to the number of fluorescence polymorphisms i(5) per chromosome. The maximum was found in chromosome 4 with $64.3 \%$ for I, 38,5\% for E, and $16.0 \%$ for $\mathrm{T}$, followed by chromosome $9(7.4 \%$, $3.4 \%, 3.3 \%)$ and chromosome $3(1.7 \%, 0 \%, 1.5$ $\%)$. The differences between investigation group $\mathrm{T}$ and $\mathrm{I}$ are significantly different for chromosome 4.

Chromosome-specific Results: The frequency of the size-polymorphism vs in the individual chromosomes groups was found to be of no significant difference in most of the cases, showing a predominant frequency between 90.5 and $100 \%$ in the 3 investigation groups E, I, and $\mathrm{T}$ (Table 2). However, a significant difference between Europeans and Turks was observed in the regions 4q11.2 and 21.p13 and a highly significant one between Indians and Turks in band 14p11.2. A highly significant difference for size vs between all 3 ethnic groups showed up only in chromosome 14, in region p11.2 as well as in p13.

The size s of polymorphisms was observed in $0-9.5 \%(\mathrm{E}, \mathrm{I}, \mathrm{T})$, revealing a significantly different interchromosomal distribution (Table 2). In the acrocentric region p11.2, the chromosomes 13 and 14 showed a significant difference

Table 1: Amount of inversions among chromosomes 1, 9, 16 and chromosomes 3 and 4 with polymorphisms of fluorescence $\mathrm{i}(5)$ (abbreviations Fig. 1; inv = inversions; polym. = polymorphisms; chr. = chromosome

\begin{tabular}{|c|c|c|c|c|c|}
\hline $\begin{array}{l}\text { Chromo- } \\
\text { some }\end{array}$ & Group & $\begin{array}{c}\text { Number of } \\
\text { chromosomes } \\
\text { analysed }\end{array}$ & $\begin{array}{c}\text { Frequency of } \\
\text { inv observed } \\
(\%)\end{array}$ & $\begin{array}{c}\text { Number of } \\
\text { polymorphisms/ } \\
\text { chromosome }\end{array}$ & $\begin{array}{l}\text { Frequency of inv } \\
\text { related to number } \\
\text { of polym./chr. (\%) }\end{array}$ \\
\hline \multirow[t]{3}{*}{1} & $\mathrm{E}$ & 200 & 0 & 9 & 0 \\
\hline & $\mathrm{I}$ & 134 & 0 & 5 & 0 \\
\hline & $\mathrm{T}$ & 200 & 0 & 21 & 0 \\
\hline \multirow[t]{3}{*}{3} & $\mathrm{E}$ & 200 & 0 & 79 & 0 \\
\hline & I & 134 & 0.8 & 58 & 1.7 \\
\hline & $\mathrm{T}$ & 200 & 0.5 & 66 & 1.5 \\
\hline \multirow[t]{3}{*}{4} & $\mathrm{E}$ & 200 & 2.5 & 13 & 38.5 \\
\hline & I & 134 & 6.7 & 14 & 64.3 \\
\hline & $\mathrm{T}$ & 200 & 2.0 & 25 & 16 \\
\hline \multirow[t]{3}{*}{9} & $\mathrm{E}$ & 200 & 0.5 & 28 & 3.4 \\
\hline & $\mathrm{I}$ & 134 & 1.5 & 27 & 7.4 \\
\hline & $\mathrm{T}$ & 200 & 0.5 & 30 & 3.3 \\
\hline \multirow[t]{3}{*}{16} & $\mathrm{E}$ & 200 & 0 & 2 & 0 \\
\hline & I & 134 & 0 & 2 & 0 \\
\hline & $\mathrm{T}$ & 200 & 0 & 6 & 0 \\
\hline
\end{tabular}


between $\mathrm{E}$ and $\mathrm{T}$, a highly significant one between I and T and none between E and I. Only $14 \mathrm{p} 11.2$ was found to be highly significantly different for all 3 ethnic groups. The acrocentric region p 13 showed a significant difference in size s for the chromosomes 13,14 , and 15 between Indians and Turks. In addition, 14 p13 was significantly different for Europeans and Indians and for all 3 groups compared, as well. Maxima for s were found in chromosome 22 with $9.5 \%$ (I and $\mathrm{T}$ ) and $7.0 \%(\mathrm{E})$ for p11.2, and 7.0\% (E), 6.0 $\%$ (I), $4.0 \%$ (T) for $\mathrm{p} 13$, the differences between the ehnic groups being insignificant.

Size $\mathrm{m}$ showed frequencies between 0 and $1.0 \%$ with a maximum in $22 \mathrm{p} 13$ and no significant differences among the ethnic groups.

Duplications of satellites (ss) were observed in a frequency of 0 to $3.0 \%$ in $15 \mathrm{p} 13$ (T), showing a significant difference between Europeans and Turks only (Table 2).

The frequency of intense fluorescence $\mathrm{i}(5)$ in a single chromosome ranged from $0 \%$ to $68.7 \%$ (maximum in chromosome 13p11.2 for I). Fluorescence polymorphisms i(5) and size vs dominated with a frequency of 68.0 to $100 \%$. Size s i(5) was observed in 0-29.6\% maximum (14p13 for I). There existed significant differences between the 3 investigation groups in the regions $13 \mathrm{p} 11.2,14 \mathrm{p} 13$, and $21 \mathrm{p} 13$ for the size vs and in 14 p13 and 21 p13 for the size s. Size $\mathrm{m}$ i(5) ranged

Table 2: Frequency of the polymorphisms of size vs, $s$ und $\mathbf{m}$ and of the polymorphisms of fluorescence i(5) of the chromosomes $3,4,13,14,15,21$, and 22 of the investigation groups E, I, and I. (abbreviations Fig. 1)

\begin{tabular}{|c|c|c|c|c|c|c|c|c|c|c|c|}
\hline \multirow{3}{*}{\multicolumn{2}{|c|}{ Chromosome }} & \multirow{3}{*}{$\begin{array}{l}\text { Group } \\
N(E)=100 \\
N(I)=67 \\
N(T)=100\end{array}$} & \multicolumn{4}{|c|}{$\begin{array}{c}\text { Frequency of the } \\
\text { polymorphisms of size (\%) }\end{array}$} & \multicolumn{5}{|c|}{$\begin{array}{l}\text { Frequency of fluorescence } i(5) \\
\text { polymorphisms in size groups }(\%)\end{array}$} \\
\hline & & & \multirow[t]{2}{*}{$v s$} & $v s$ & \multirow[t]{2}{*}{$s$} & \multirow[t]{2}{*}{$m$} & \multirow[t]{2}{*}{ in all } & \multicolumn{4}{|c|}{ of those } \\
\hline & & & & ss & & & & $v s$ & $v s s s$ & $s$ & $m$ \\
\hline \multirow[t]{3}{*}{3} & \multirow[t]{3}{*}{ q11.2 } & $\mathrm{E}$ & - & - & - & - & 39.5 & 100 & - & 0 & 0 \\
\hline & & I & - & - & - & - & 43.3 & 96.6 & - & 3.4 & 0 \\
\hline & & $\mathrm{T}$ & - & - & - & - & 33 & 100 & - & 0 & 0 \\
\hline \multirow[t]{3}{*}{4} & \multirow[t]{3}{*}{$\mathrm{q} 11.2$} & $\mathrm{E}$ & - & - & - & - & 6.5 & 92.2 & - & 7.8 & 0 \\
\hline & & I & - & - & - & - & 10.5 & 92.9 & - & 7.1 & 0 \\
\hline & & $\mathrm{T}$ & - & - & - & - & 12.5 & 100 & - & 0 & 0 \\
\hline \multirow[t]{6}{*}{13} & \multirow[t]{3}{*}{$\mathrm{p} 11.2$} & $\mathrm{E}$ & 95 & - & 5 & 0 & 63.5 & 93.7 & - & 6.3 & 0 \\
\hline & & $\bar{I}$ & 94.8 & - & 5.2 & 0 & 68.7 & 93.5 & - & 6.5 & 0 \\
\hline & & $\mathrm{T}$ & 93.5 & - & 6.5 & 0 & 44.5 & 85.4 & - & 14.6 & 0 \\
\hline & \multirow[t]{3}{*}{ p 13} & $\mathrm{E}$ & 96.5 & 0.5 & 3 & 0 & 11.5 & 77 & 0 & 23 & 0 \\
\hline & & I & 94.8 & 0 & 5.2 & 0 & 21.7 & 75.9 & 0 & 24.1 & 0 \\
\hline & & $\mathrm{T}$ & 98.5 & 0 & 1 & 0.5 & 15 & 90 & 0 & 6.7 & 3.3 \\
\hline \multirow[t]{6}{*}{14} & \multirow[t]{3}{*}{$\mathrm{p} 11.2$} & $\mathrm{E}$ & 97 & - & 3 & 0 & 1 & 100 & - & 0 & 0 \\
\hline & & I & 94 & - & 6 & 0 & 1.5 & 100 & - & 0 & 0 \\
\hline & & $\mathrm{T}$ & 100 & - & 0 & 0 & 0.5 & 100 & - & 0 & 0 \\
\hline & \multirow[t]{3}{*}{ p 13} & $\mathrm{E}$ & 98 & 0.5 & 1.5 & 0 & 21 & 92.9 & 0 & 7.1 & 0 \\
\hline & & $\mathrm{I}$ & 94 & 0 & 6 & 0 & 20.2 & 70.4 & 0 & 29.6 & 0 \\
\hline & & $\mathrm{T}$ & 99 & 0 & 1 & 0 & 12.5 & 92 & 0 & 8 & 0 \\
\hline \multirow[t]{6}{*}{15} & \multirow[t]{3}{*}{$\mathrm{p} 11.2$} & $\mathrm{E}$ & 96,5 & - & 3.5 & 0 & 0.5 & 100 & - & 0 & 0 \\
\hline & & I & 97 & - & 3 & 0 & 2.2 & 100 & - & 0 & 0 \\
\hline & & $\mathrm{T}$ & 99 & - & 1 & 0 & 0 & 0 & - & 0 & 0 \\
\hline & \multirow[t]{3}{*}{ p 13} & $\mathrm{E}$ & 95.5 & 0.5 & 3.5 & 0.5 & 23.5 & 83 & 0 & 14.9 & 2.1 \\
\hline & & $\mathrm{I}$ & 94.8 & 0 & 5.2 & 0 & 21.6 & 75 & 0.8 & 24.1 & 0 \\
\hline & & $\mathrm{T}$ & 96 & 3 & 1 & 0 & 12.5 & 91.5 & 0.5 & 8 & 0 \\
\hline \multirow[t]{6}{*}{21} & \multirow[t]{3}{*}{ p11.2 } & $\mathrm{E}$ & 100 & - & 0 & 0 & 0.5 & 100 & - & 0 & 0 \\
\hline & & I & 100 & - & 0 & 0 & 1.5 & 100 & - & 0 & 0 \\
\hline & & $\mathrm{T}$ & 99.5 & - & 0.5 & 0 & 0 & 0 & - & 0 & 0 \\
\hline & p 13 & $\mathrm{E}$ & 97.5 & 0 & 2.5 & 0 & 20.5 & 90.2 & 0 & 9.8 & 0 \\
\hline & & I & 96.3 & 0 & 3.7 & 0 & 32.8 & 88.6 & 0 & 11.4 & 0 \\
\hline & & $\mathrm{T}$ & 93.5 & 0 & 6 & 0.5 & 21 & 71.4 & 0 & 26.2 & 2.4 \\
\hline 22 & p11.2 & $\mathrm{E}$ & 92.5 & - & 7 & 0.5 & 9 & 88.8 & - & 5.6 & 5.6 \\
\hline & & $\mathrm{T}$ & 90.5 & - & 9.5 & 0 & 4 & 100 & - & 0 & 0 \\
\hline & & $\mathrm{T}$ & 90.5 & - & 9.5 & 0 & 4 & 100 & - & 0 & 0 \\
\hline & p 13 & $\mathrm{E}$ & 92 & 0 & 7 & 1 & 23.5 & 68 & 0 & 27.7 & 4.3 \\
\hline & & I & 94 & 0 & 6 & 0 & 30.6 & 80.5 & 0 & 19.5 & 0 \\
\hline & & $\mathrm{T}$ & 94.5 & 0.5 & 4 & 1 & 24 & 81.2 & 0 & 14.6 & 4.2 \\
\hline
\end{tabular}


from 0 to $5.6 \%$ with maxima for 22 (p11.2 for $\mathrm{E})$ (Table 2).

The polymorphic regions of the chromosomes 3 and 4 with a brilliant fluorescence are included in the analysis of size variations, size vs dominating with a frequency of 92.2 to $100 \%$, followed by $\mathrm{s}$ in 0 to $7.8 \%$. Size $\mathrm{m}$ was not observed (Table 2).

Comparison of the 3 Ethnic Groups: The comparison of the polymorphisms among the 3 ethnic groups showed distinct inter- and intrachromosomal differences (Table 2).

Primarily, this concerned the size of the polymorphic regions, affecting 12 out of 20 characters: 1q12, 4q11.2, 13p11.2 and p13, 14p11.2 and $\mathrm{p} 13,15 \mathrm{p} 13,21 \mathrm{p} 13$ as well as the band $\mathrm{p} 12$ in all but one (13) of the acrocentric chromosomes. With regard to a comparison of the polymorphic bands in the autosomes of the 3 different ethnic groups with one another (one region in the autosomes 1, 3, 4, 9, 16 each and three in the individual acrocentric chromosomes), there were found to be 147 different combinations, considering the different sizes. $26(17.7 \%)$ of those variations were significantly different among the 3 ethnic groups, 4 on the autosomes $1,3,4,9,16$, and 22 on the acrocentrics. The distribution of the difference of size for the combinations E/I, E/T, and I/T among the ethnic groups revealed $5(3.4 \%)$ different features for E/I, $7(4.8 \%$ ) for E/T, and $14(9.5 \%)$ for I/T (Table 3).

Significant differences in the fluorescence $i$ (5) were observed in 3 out of 12 regions: $13 \mathrm{p} 11.2$, $14 \mathrm{p} 13$, and $21 \mathrm{p} 13$. Of the 123 various combinations comparing 2 of the 3 ethnic groups, there were $7(5.7 \%)$ significantly different variants, $1(0.8 \%)$ for $\mathrm{E} / \mathrm{I}, 4(3.3 \%)$ for $\mathrm{E} / \mathrm{T}$, and $2(1.6 \%)$ for $\mathrm{I} / \mathrm{T}$.

A comparison of both, size and fluorescence $i(5)$, indicated the difference of features between the Turks and Indians to be the highest with 16 variants, followed by 11 for Europeans and Turks. The difference among Europeans and Indians proved to be the smallest with 6 regions (Table 3).

There were distinct interchromosomal differences for all 3 ethnic groups regarding the 3 polymorphic bands of the short arms of the acrocentric chromosomes. Chromosome 14 showed differences in all 3 regions, as far as size was concerned, chromosomes 13,15 , and 21 in 2 regions and chromosomes 22 in one. The region p12 showed highly significant differences in all but chromosome 13 in the comparison of the Indian group to the Turks and Europeans. In chromosome 14 p11.2 and p12, more than half of the differences found between the ethnic groups was highly significant.

The 3 bands of the acrocentric chromosomes displayed various frequencies of difference with 8 in p11.2 and p12 each and 14 in p13.

Only chromosome 14 was found to show a significant difference in the comparison of all three ethnic groups.

With just one of each, mutations like inversions or duplications of satellites proved to be of no importance for ethnic differentiation of the 3 groups (Table 3 ).

Summarizing the results of fluorescence i(5) in polymorphisms of size and inversions regarding the acrocentrics and chromosomes 3 and 4, the slightest difference could be found between Europeans and Indians, followed by difference between Europeans and Turks, while Indians and Turks revealed the highest differences in this specific group of polymorphisms.

\section{DISCUSSION}

There are various publications on polymorphisms of the human constitutive heterochromatin with applications of different methods (staining or scale) taking only part of the potential polymorphisms into account thus causing a comparison of the results to be difficult.

The present study analysed the constitutive heterochromatic regions of the chromosomes 1 , $3,4,9,13,14,15,16,21,22$, and $Y$ of 267 persons of different ethnic origin (Central European, Indian, and Turkish). The 10,680 possible polymorphisms were composed of 6,408 regions of fluorescence polymorphisms i(5) and of the variations of the sizes vs, $s$, and $m$ of the bands $1 q 12,3 q 11.2,4 q 11.2,9 q 12,16 q 11.2$, and the acrocentrics with the regions $\mathrm{p} 11.2, \mathrm{p} 12$, and $\mathrm{p} 13$ plus the polymorphism of length possible in the 2,670 chromosomes. Within those autosomes, 5,582 regions showed a polymorphism of size, 1,168 bands a polymorphism of fluorescence $i(5)$, 67 of 2,670 regions of the acrocentrics exhibited a polymorphism of length of $\mathrm{p} 12$ and 12 region showed a polymorphism of structure in $\mathrm{p} 13$ (double satellites). Furthermore, 130 of 534 bands displayed a duplication of the constititive 
Table 3: Significant and highly significant differences in the comparison of the 3 ethnic groups E, I, and $T$ regarding the polymorphisms of size $v s$, $s$, and $m$, of fluorescence $i(5)$, and of duplications and inversions (abbreviations Fig. 1; ss = double satellite; $S=$ statistically different; $H S=$ statistically highly different).

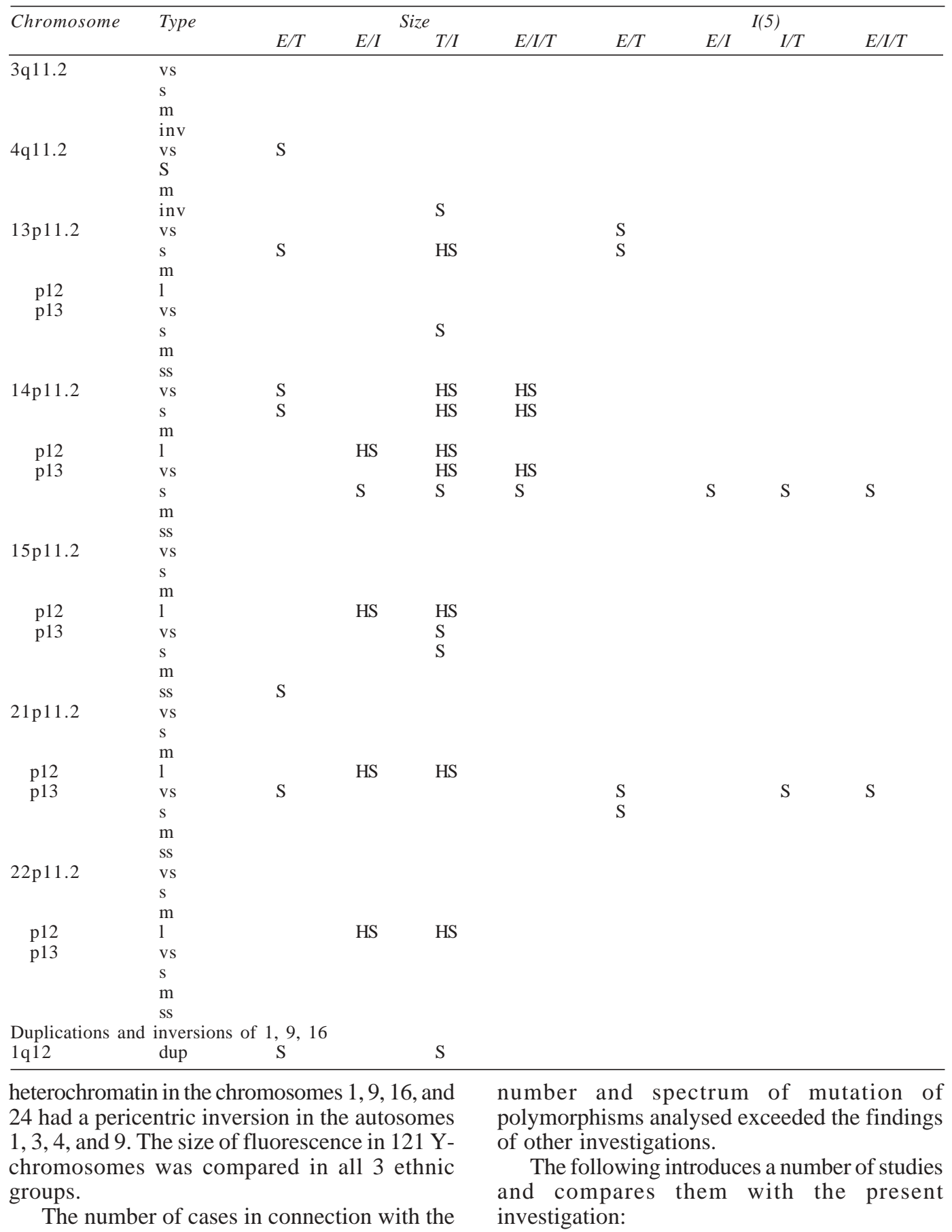


Barker et al. (1977) studied 5 metaphases each of 108 persons in California on photographs of Q-metaphases after amniocyte culture without stating their ethnic origin. Included were the chromosomes $3,4,13,14,15,21$, and 22. In the acrocentrics the polymorphic regions were defined as short arm and satellites. The intensity of fluorescence of these regions was compared to the fluorescence of the distal region of the long arm of chromosome 13. There was no differentiation of size of the polymorphic bands. The frequency of variants per person ranged from 0 to 11 with an average of 4 . These findings are in accordance with the number of fluorescence polymorphisms per case in the present study of Europeans after lymphocyte culture. The most frequent polymorphism in Barker's study was the intense fluorescence of the short arm of chromosome 13 , followed by the centromeric region of chromosome 3 and the satellites of chromosome 21 (without defining these regions as $\mathrm{p} 11.2, \mathrm{q} 11.2$, and $\mathrm{p} 13$ according to ISCNNomenclature). The results are comparable to our findings in the Indian group (13p11.2 $=68.7 \%$, $3 \mathrm{q} 11.2=43.3 \%, 21 \mathrm{p} 13=32.8 \%$ ).

Barker et al. compared their results with studies performed by Geraedts and Pearson (1974) on a Dutch group $(\mathrm{N}=221)$ and found similar frequencies of polymorphisms even though Geraedts and Pearson did not differentiate between separate observations for p11.2 and p13 of the D and G chromosomes. An additional comparison with a Danish study ( $\mathrm{N}=$ 90) by Hauge et al. (1975) showed multiple discrepancies to the results of Barker on the one hand and Geraedt's and Pearson's on the other and was explained by the authors with differences in technique and evaluation of the variants. Erdtmann et al. (1981) measured the size of Cbands in chromosomes 1,9 , and 16 after lymphocyte culture densitometrically in 10 cells each and corrected the varying condensation of the different chromosomes by comparing them with the length of the long arm of chromosome 1 of the same metaphase. The collection consisted of 394 natives of various Southern American tribes and 40 Brasilian Caucasians. Variability among the groups could not be detected and the differences among the groups did not follow an unequivocal pattern. The relative size of the $\mathrm{C}$ bands of the chromosomes 1,9 , and 16 was very similar in natives and Caucasians alike. This investigation corresponds to our results for chromosomes 9 and 16 with no significant differences for all 3 ethnic groups. Chromosomes 1 in the present study did not show any significant differences in the comparison of the European to the Indian group but did exhibit a significant difference in the Turkish group versus the European and the Indian and among the 3 groups (Kalz 2003). Zanenga et al. (1984) compared C-bands prepared according to the procedure of Erdtmann et al. of the chromosomes $1,9,16$, and $Y$ of 38 Blacks and 38 Caucasians in Brazil. The C-bands in the chromosomes 1, 9, and 16 of the Blacks were smaller than in the Caucasians but of similar size for the Ychromosome of both groups.

In the study of Olson et al. (1986), an inversion of the heterochromatin was found in chromosome 4 in 13 of 39 persons $(33.3 \%)$ and in chromosome 3 in 3 of $39(7.7 \%)$. The present study showed a relative frequency of the complete pericentric inversion, refering to the number of chromosomes analysed, in $38.5 \%$ (E), $16.0 \%$ (T), and $64.3 \%$ (I) for chromosome 4 and $0 \%(\mathrm{E}), 1.5 \%(\mathrm{~T})$, and 1.7 $\%$ (I) for chromosome 3 . The difference of the 3 ethnic groups is highly significant. There are similarities between our European Group and Olson's, as far as chromosome 4 is concerned.

Hsu et al. (1987) analysed the polymorphisms of the constitutive heterochromatin of the chromosomes 1, 9 , and 16 by GTG-staining, with additional QFQ- and CBG- banding if necessary. Following amniotic culture, they evaluated 6250 persons belonging to 4 different ethnic groups: white Americans, Afro-Americans, Americans of Hispanic origin and Americans of Asian or Indian origin, choosing the short arm of chromosome 16 as the standard of size for polymorphisms in 1,9 , and 16. But according to our studies (Kalz et al. 2004), frequencies in amniocytes and lymphocytes are different. Their results showed differences of frequency for the pericentric inversion of chromosome 9 between the 4 ethnic groups: $3.6 \%$ for the Afro-Americans, $2.4 \%$ for the Hispanics, 0.7 for the white Americans, and $0.3 \%$ for the Asians. The findings of our study showed similarities in the frequency of pericentric inversions of chromosome 9 of the European group $(0.5 \%)$, compared with the ,white " group of Hsu's $(0.7 \%)$, and for the Turks $(0.5 \%)$ with the Asian group of Hsu's with $0.5 \%$. The frequency in our Indian group was higher (1.5 $\%)$ than the Asian/Indian group in Hsu's study $(0.3 \%)$.

Rosser et al. (2000) performed a study of the 
relationship between genetics, geography, and language by analysing and comparing 11 biallelic markers of the Y-chromosomes of 3616 men in 47 populations. They chose the Y-chromosome because of patrilocality in marriage that was a better indication of migration of populations than the autosomes are. No single subgroup revealed the distribution of frequency of the collective one. The results showed a strong and highly significant correlation between the pattern of the genetic markers of the Y-chromosome and the geographic origin of the groups and a low and not significant correlation with the language. The results found in our study showed an significant difference in the length of Yq12 in size categorie $\mathrm{Y}=20 \%$ between the Europeans and the Turks, a significant one between Europeans and Indians, and Turks and Indians respectively but with no significant difference in any other sizes of the region.

The comparisons of these studies demonstrated that population genetic analyses of polymorphisms can reveal similarities or differences in ethnic groups. It is obvious, though, that the validity of comparisons of different studies is limited. The sizes of the groups and the ethnic structure vary immensely.
A Dutch group (Geraedts and Pearson) and a Danish one (Hauge et al.) are not equal to the group from California (Barker et al.). Additionally, the Dutch and Danish studies are not comparable to each other and to the European group of this study because of difference in data collection. The Turkish analyses of Y-chromosomes (Rosser et al. 2000) have no similarities with our study. The analyses of C-bands on the chromosomes 1 , 9, and 16 in Brazil (Zanenga et al.) give no conclusive testimony about $\mathrm{C}$-bands of centromeric regions of other chromosomes, a statement the authors regret to make themselves.

Table 4 shows a comparison of relative frequencies of fluorescence polymorphisms after QFQ-staining of a postnatal study of the chromosomes 3 and 4 and the bands p11.2 and p13 of the short arm regions of the chromosomes $13,14,15,21$, and 22, analysed by Barker et al. (1977), Buckton et al. (1976), Kalz (2003), Lin et al. (1976), Lubs (1977), Müller and Klinger (1975), and Müller and Klinger II (1975). Some authors characterize $\mathrm{p} 11.2$ as $\mathrm{p}$ and $\mathrm{p} 13$ as s. The extensive studies of Mikelsaar as well as Geraedts (Mikelsaar et al.,1973, 1974, 1975; Geraedts and Pearson 1974) are not included, since Mikelsaar et al. stained with Atebrin and Geraedts and

Table 4: Comparison of frequencies of fluorescence $i(5)$ on the chromosomes $3,4,13,14,15,21$, and 22, according to studies from the literature (abbreviations Fig. 1).

\begin{tabular}{|c|c|c|c|c|c|c|c|c|c|c|c|c|}
\hline \multirow[t]{3}{*}{ Group Postnatal } & \multirow[t]{3}{*}{$N$} & \multicolumn{11}{|c|}{ Chromosome region } \\
\hline & & \multirow{2}{*}{$\frac{3}{q 11.2}$} & \multirow{2}{*}{$\frac{4}{q 11.2}$} & \multicolumn{2}{|c|}{13} & \multicolumn{2}{|c|}{14} & \multicolumn{2}{|c|}{15} & 21 & \multicolumn{2}{|c|}{22} \\
\hline & & & & $p 11.2$ & $p 13$ & $p 11.2$ & $p 13$ & p11.2 & $p 13$ & $p 11.2$ p13 & $p 11.2$ & p 13 \\
\hline $\begin{array}{l}\text { Canada } \\
\text { Lin et al., } 1976\end{array}$ & 930 & 55,5 & 14,1 & 31,4 & 1,9 & 0,8 & 0,2 & 0,2 & 0,9 & $0,1 \quad 1,1$ & 0,3 & 0,3 \\
\hline $\begin{array}{l}\text { USA, white } \\
\text { Müller } u \text {. Klinger, } 1975\end{array}$ & 222 & 54,4 & 12,8 & 73,8 & 9,8 & 3,2 & 9,3 & 3,2 & 7,4 & $3,516,2$ & 19,2 & 23,9 \\
\hline $\begin{array}{l}\text { USA, white } \\
\text { Lubs, } 1977\end{array}$ & 205 & 50,3 & 10,6 & 29,5 & 2,0 & - & 5,7 & 0,5 & 5,1 & $0,3 \quad 4,1$ & 1,0 & 3,0 \\
\hline $\begin{array}{l}\text { USA, black } \\
\text { Müller } u \text { Klinger } 1975\end{array}$ & 39 & 67,5 & 17,6 & 79,7 & 10,8 & 0 & 13,5 & 1,4 & 8,1 & $5,417,6$ & 27,0 & 37,8 \\
\hline $\begin{array}{l}\text { USA, black } \\
\text { Lubs, } 1977\end{array}$ & 210 & 58,2 & 4,6 & 50,3 & 5,1 & - & 6,7 & 1,5 & 5,1 & $1,0 \quad 6,7$ & 2,0 & 7,3 \\
\hline $\begin{array}{l}\text { USA } \\
\text { Müller u. Klinger II, } 1975\end{array}$ & 376 & 55,0 & 13,0 & - & 8,2 & - & 13,4 & - & 11,0 & $2,617,0$ & 34,0 & 28,0 \\
\hline $\begin{array}{l}\text { USA } \\
\text { McKenzie u. Lubs, } 1975\end{array}$ & 77 & 40,9 & 40,9 & 44,2 & 2,6 & 0 & 4,6 & 0 & 1,3 & $0 \quad 2,6$ & 7,1 & 2,0 \\
\hline $\begin{array}{l}\text { Schottland, random } \\
\text { Buckton et al., } 1976\end{array}$ & 149 & 58,3 & 18,1 & 21,2 & 11,2 & - & 6,0 & - & 10,5 & $0,3 \quad 4,9$ & 1,0 & 11,6 \\
\hline $\begin{array}{l}\text { Central Europe } \\
\text { Kalz, } 2001\end{array}$ & 100 & 39,5 & 6,5 & 63,5 & 11,5 & 1,0 & 21,0 & 0,5 & 23,5 & $0,520,5$ & 9,0 & 23,5 \\
\hline $\begin{array}{l}\text { Turkey } \\
\text { Kalz, } 2001\end{array}$ & 100 & 33,0 & 12,5 & 44,5 & 15,0 & 0,5 & 12,5 & 0 & 12,5 & 021,0 & 4,0 & 24,0 \\
\hline $\begin{array}{l}\text { India } \\
\text { Kalz, } 2001\end{array}$ & 67 & 43,3 & 10,5 & 68,7 & 21,7 & 1,5 & 20,2 & 2,2 & 21,6 & $1,532,8$ & 19,4 & 30,6 \\
\hline
\end{tabular}


Pearson did not specify the bands p11.2 and p13 in the short arms of the acrocentrics in any way. The observations of Lin et al. in the Canadian group tend to give low frequencies of fluorescence polymorphisms while the statements of Müller and Klinger about a group of Whites in the USA are high. The investigations in our study fit in between those extremes for the regions 3q11.1, 4q11.1, 13p11.2, 14p11.2, 15p11.2, $21 \mathrm{p} 11.2$ and 22p11.2 and p13, but show higher frequencies in all 3 ethnic groups for $13 \mathrm{p} 13,14 \mathrm{p} 13$, $15 \mathrm{p} 13$ and $21 \mathrm{p} 13$. This result may be attributed to the fact that the analyses were conducted on negatives instead of on prints, thus allowing higher accuracy.

In general, a comparison of studies can only be conclusive if it is using the same cell system and the same method of evaluation. The importance of a comprehensive and uniform methodology in the cytogenetic study of the polymorphisms of the constitutive heterochromatin in the entire human genome must be emphasized.

Our investigations enabled us to delineate marked differences in many polymorphisms between our collective groups of Europeans, Indians, and Turks reflecting different relations between those 3 groups. In accordance with anthropological and linguistic findings, we were able to show closer relations between Europeans and Indians, more distant ones between Europeans and Turks and most distant relations between Indians and Turks.

\section{SUMMARY}

Polymorphisms of constitutive heterochromatin in the chromosomes 1, 3, 4, 9, 13, 14, $15,16,21,22$ and Y of 100 non-related Central Europeans (E) were compared to those of 67 persons from Southern India (I) and 100 from Turkey (T) in a similar distribution of male and female cases using lymphocyte culture and focusing predominantly on fluorescence polymorphisms i(5) after QFQ-banding. Differences in polymorphisms of size were insignificant for the sizes very small (vs) and medium (m) but significantly different for small (s) with the highest amounts in the Indian group ( $I=4.8$ $\%, \mathrm{E}=3.5 \%, \mathrm{~T}=2.9 \%)$. Differences in fluorescence polymorphisms i(5) proved to be statistically highly significant with $22.8 \%$ (I), 18.5 $\%(\mathrm{E})$, and $14.9 \%(\mathrm{~T})$ of the total number of chromosomes analysed and $26.0 \%$ (I), $21.2 \%$
(E), and $17.2 \%(\mathrm{~T})$ refering to chromosomes with fluorescence $i(5)$ and defined structural polymorphisms together. The number of fluorescence $\mathrm{i}(5)$ per case showed a maximum of 5 in group I, 4 in group E, and 3 in group T. In all 3 groups, the average size of $\mathrm{Yq} 12 \mathrm{had}$ a maximum at $39 \%$ of the total length of the chromosome. Polymorphisms of size after QFQ- and CBGstaining in the chromosomes 1,9 , and 16 revealed statistically different results between $\mathrm{E}$ and $\mathrm{T}$ (19.5 and $28.5 \%$ ) and $\mathrm{T}$ and I (28.5 and $25.4 \%$ ) and none between $\mathrm{E}$ and I. Duplication of the satellite stalk (p12) of the acrocentric chromosomes showed a highly significant difference between $\mathrm{E}$ and $\mathrm{I}$ as well as T and I and a significant difference between $\mathrm{E}$ and $\mathrm{T}$ with 8.4 $\%$ for I, $1.0 \%$ for E, and $0.1 \%$ for T. Doubled satellites (ss) in p13 of the acrocentric chromosomes were diagnosed with no significant differences. Analyses of complete pericentric inversions of the constitutive heterochromatin showed a significant difference between the groups I and T (64.3\% and $16.0 \%)$, refering to chromosomes with polymorphisms only and none between $\mathrm{E}$ and $\mathrm{I}$ or $\mathrm{E}$ and $\mathrm{T}$.

The investigation of chromosome-specific results in the individual chromosomes for all 3 ethnic groups showed no significant difference in most of the cases. But there were distinct interchromosomal differences regarding the size of the 3 polymorphic bands in the short arms of the acrocentric chromosomes. Chromosome 14 showed differences in all 3 regions, chromosomes 13,15 , and 21 in 2 regions and chromosome 22 in one. The region $\mathrm{p} 12$ was found to have highly significant differences in all but chromosome 13 in the comparison of the Indian group to the Europeans and Turks. In chromosome 14p11.2 and p12, more than half of the differences found between the ethnic groups were highly significant. Inversions or duplications were of no importance for ethnic differentiation of the 3 groups.

The comparison of the differences in polymorphisms of size and fluorescence as well as duplications and inversions showed the least amount of differences to exist between Europeans and Indians, followed by Europeans and Turks, with Turks and Indians having the highest number of significant differences. The distribution of difference of size for the combinations $\mathrm{E} / \mathrm{I}, \mathrm{E} / \mathrm{T}$, and $\mathrm{I} / \mathrm{T}$ revealed 5 different features for E/I, 7 for $\mathrm{E} / \mathrm{T}$ and 14 for $\mathrm{I} / \mathrm{T}$. As to the 
significant difference in the fluorescence i(5), 1 variant was significantly different for E/I, 4 for E/ $\mathrm{T}$, and 2 for $\mathrm{I} / \mathrm{T}$. A comparison of both features indicated 6 differences for E/I, 11 for E/T, and 16 for $\mathrm{I} / \mathrm{T}$.

\section{REFERENCES}

Barker PE, Mohandas T, Kaback MM 1977. Chromosome polymorphisms in karyotypes from amniotic fluid cell cultures. Clin Genet, 11: 243248 .

Buckton KE, O'Riordon ML, Jacobs PA et al. 1976. Cand Q-band Polymorphisms in the chromosomes of three human populations. Ann Hum Genet, 40: 99-112.

Erdtmann B, Salzano FM, Mattevi MS et al. 1981. Quantitative analysis of $\mathrm{C}$ bands in chromosomes 1,9 and 16 of Brazilian Indians and Caucasoids. Hum Genet, 57: 58-63.

Geraedts JPM, Pearson PL 1974. Fluorescent chromosome polymorphisms: frequencies and segregations in a Dutch population. Clin Genet, 6: 247-257.

Hauge M, Poulsen H, Halberg A et al. 1975. The value of fluorescence markers in the distinction between maternal and fetal chromosomes. Humangenetik, 26: $187-191$

Hsu LYF, Benn PA, Tannenbaum HL et al. 1987. Chromosomal polymorphisms of $1,9,16$, and $\mathrm{Y}$ in 4 major ethnic groups: A large prenatal study. Am J Med Genet, 26: 95-101.

Kalz L 2003. Chromosomenpolymorphismen des konstitutiven Heterochromatins im Karyotyp des Menschen. Untersuchungen zu ihrer Häufigkeit und zur Mutationsfrequenz der verschiedenen Regionen unter Berücksichtigung der ethnischen Herkunft. Shaker, Aachen.

Kalz L, Schwanitz G. 2004. Characterization of constitutive heterochromatin, in particular of fluorescence polymorphisms, in a Central European population. Int J Hum Genet, 4(1): 1-10.

McKenzie WH, Lubs HA 1975. Human Q and C chromosomal variations: Distribution and incidence. Cytogenet. Cell Genet, 14: 97-115.

Mikelsaar A-VN, Tüür SJ, Käosaar ME 1973. Human karyotype polymorphism. I. Routine and fluorescence microscopic investigation of chromosomes in a normal adult population. Humangenetik, 20: 89-101.

Mikelsaar A-VN, Viikmaa MH, Tüür SJ et al. 1974. Human karyotype polymorphism. II. The distribution of individuals according to the presence of brilliant bands in chromosomes 3, 4, and 13 in a normal adult population. Humangenetik, 23: 5963.

Mikelsaar A-VN, Käosaar ME, Tüür SJ 1975. Human karyotype polymorphism. III. Routine and fluorescence microscopic investigation of chromosomes in normal adults and mentally retarded children. Humangenetik, 26: 1-23.

Müller HJ, Klinger HP Glasser M 1975. Chromosome polymorphism in a human newborn population. II. Potentials of polymorphic chromosome variants for characterizing the idiogram of an individual. Cytogenet Cell Genet, 15: 239-255.

Olson SB, Magenis RE, Lovrien EW 1986. Human chromosome variation: The discriminatory power of Q-band heteromorphism (variant) analysis in distinguishing between individuals, with specific application to cases of questionable paternity. Am J Hum Genet, 38: 235-252.

Patil SR, Lubs HA 1977. Classification of qh regions in human chromosomes 1,9 , and 16 by C-banding. Hum Genet, 38: 35-38.

Rosser ZH, Zerjal T, Hurles ME et al. 2000. Ychromosomal diversity in Europe is clinal and influenced primarily by geography, rather than by language. Am J Hum Genet, 67: 1526-1543.

Zanenga R, Mattevi MS, Erdtmann B 1984. Smaller autosomal $\mathrm{C}$ band size in Blacks than in Caucasoids. Hum Genet, 66: 286. 